\title{
Transformational Leadership and Satisfaction in Sports: Examination of the Influence of Leadership Substitute Variables
}

\begin{abstract}
Using Kerr and Jermier's (1978) leadership substitutes theory as framework, this study examined the extent to which situational variables moderate the relationship between transformational leadership behaviours and coaches' job satisfaction at NCAA Division III institutions. Data for this study were collected from a national sample of 308 coaches from NCAA Division III institutions. The Transformational Leadership Behaviour Inventory developed by Podsakoff, MacKenzie, Moorman, and Fetter (1990) was used to measure coaches' perception of the transformational leadership behaviours of their athletic directors. Coaches' perception regarding the existence of situational variables was measured by using the Substitutes for Leadership Questionnaire developed by Kerr and Jermier (1978). The job satisfaction of coaches was measured by using the Minnesota Satisfaction Questionnaire (Weiss, Dawis, England \& Lofquist, 1967). Data were analysed using descriptive statistics and logistic regression. The results suggest that there is a significant relationship between transformational leadership behaviours of athletic directors and coaches' job satisfaction at NCAA Division III institutions. It was discovered that situational variables such as coaching ability, organisational formalization, and group cohesion were significantly related with coaches' job satisfaction. Professional orientation was discovered to be a leadership neutralizer, while group cohesion to be a substitute of transformational leadership behaviours. It was concluded that transformational leadership behaviours of athletic directors have a direct relationship with coaches' job satisfaction in the absence of a strong leadership substitute or neutralizer. However, in the presence of leadership substitute and neutralizer, transformational leadership behaviours influence coaches' job satisfaction indirectly, through the moderating effects of the substitute and neutralizer.
\end{abstract}

Keyword: Transformational Leadership, Leadership Substitutes, Job Satisfaction 